\title{
The role of adrenergic receptor polymorphisms in heart failure
}

\section{A. Biolo ${ }^{1}$, A.S. Rosa ${ }^{1}$,}

N.G. Mazzotti ${ }^{1}$, S. Martins ${ }^{1}$,

A. Belló-Klein ${ }^{2}$, L.E. Rohde ${ }^{1}$ and N. Clausell ${ }^{1}$

\author{
${ }^{1}$ Grupo de Insuficiência Cardíaca e Transplante, Serviço de Cardiologia, \\ Hospital de Clínicas de Porto Alegre, Porto Alegre, RS, Brasil \\ ${ }^{2}$ Laboratório de Fisiologia Cardiovascular, Departamento de Fisiologia, \\ Instituto de Biociências, Universidade Federal do Rio Grande do Sul, \\ Porto Alegre, RS, Brasil
}

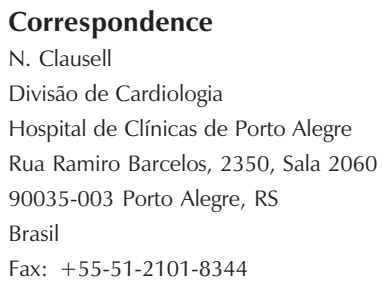

\begin{abstract}
The main function of the cardiac adrenergic system is to regulate cardiac work both in physiologic and pathologic states. A better understanding of this system has permitted the elucidation of its role in the development and progression of heart failure. Regardless of the initial insult, depressed cardiac output results in sympathetic activation. Adrenergic receptors provide a limiting step to this activation and their sustained recruitment in chronic heart failure has proven to be deleterious to the failing heart. This concept has been confirmed by examining the effect of $\beta$-blockers on the progression of heart failure. Studies of adrenergic receptor polymorphisms have recently focused on their impact on the adrenergic system regarding its adaptive mechanisms, susceptibilities and pharmacological responses. In this article, we review the function of the adrenergic system and its maladaptive responses in heart failure. Next, we discuss major adrenergic receptor polymorphisms and their consequences for heart failure risk, progression and prognosis. Finally, we discuss possible therapeutic implications resulting from the understanding of polymorphisms and the identification of individual genetic characteristics.
\end{abstract}

Key words

- Heart failure

- Adrenergic receptor

- Polymorphisms

\section{Introduction}

Heart failure (HF) is a significant health problem worldwide and despite many recent advances in treatment, HF-related morbidity and mortality remain elevated (1). Regardless of the initial insult, depressed cardiac output results in sympathetic activation. Several experimental and clinical studies have demonstrated that this sustained adrenergic drive can be deleterious to the failing heart, contributing to HF progression, perpetuation and presentation (2). This concept has been confirmed by the benefits of B-blockers in patients with heart failure (3-5). Advances in the knowledge of specific molecular characteristics and adaptations of the adrenergic system have permitted a better understanding of its role in the development and progression of heart failure (6).

\section{The adrenergic system in the healthy heart}

The adrenergic system, or sympathetic autonomous nervous system, is responsible 
for a variety of adaptive events that occur in response to increases in oxygen and nutrient demands. The system consists of nervous structures, neurotransmitters, vasoactive substances, hormones, and specific receptors (adrenergic receptors, AR). The heart and peripheral circulation undergo short-term modifications to regulate cardiac output, arterial pressure and blood flow distribution as a result of the interaction between the central nervous center and peripheral effector structures. When acutely activated, the sympathetic nervous system stimulates the release of neurotransmitters and vasoactive substances, regulating cardiac output and promoting blood flow redistribution and arterial pressure modifications, respectively (7). AR are key signaling elements regulating the intensity of adrenergic activation (Figure 1) (8).

AR are transmembrane proteins of myocardial cells that act by coupling to a Gprotein, which in turn can be excitatory $\left(\mathrm{G}_{\mathrm{s}}\right)$ or inhibitory $\left(\mathrm{G}_{\mathrm{i}}\right)$. They represent the limiting stage of the cardiac response to an adrenergic stimulus. When norepinephrine binds to the AR, a cascade of events is immediately triggered to obtain an intracellular response. A kinase-dependent pathway regu-
Figure 1. Representation of a synaptic gap with the main components of the cardiac adrenergic signaling. Release of norepinephrine is regulated by presynaptic $\alpha 2 \mathrm{c}$-adrenergic receptor (AR). After being released, norepinephrine binds to $B-A R$, that are G-protein-coupled transmembrane receptors. On binding to ligands, the stimulatory G-protein $\left(G_{s}\right)$ activates adenylate cyclase and the inhibitory $\mathrm{G}$-protein $\left(\mathrm{G}_{\mathrm{i}}\right)$ reduces its activity. Both B1- and B2-AR are normally coupled to $G_{S}$ protein, but B2-AR may also couple to $G_{i}$. The stimulation and function of these receptors modulate effector molecules responsible for regulating cardiomyocyte contraction and hypertrophy (8).

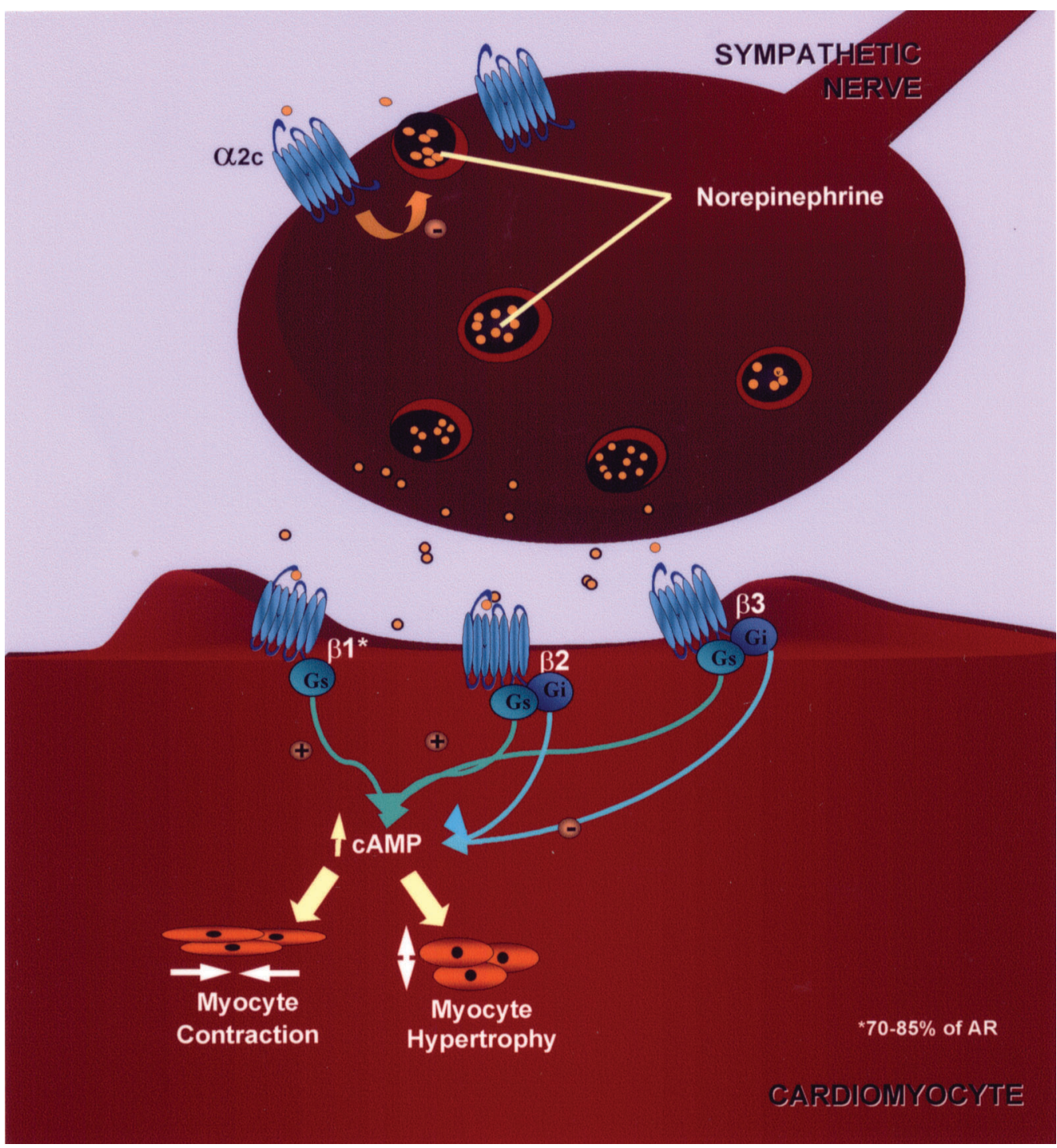


lates the inotropic and chronotropic cardiac response.

There are two principals AR: $\alpha$ and $\beta(6,9)$. The $\alpha$-AR are subdivided into two classes. The post-synaptic $\alpha 1$-AR plays a role in hypertrophy and myocardial remodeling whereas the $\alpha 2$-AR is pre-synaptic in the heart and its main function is to inhibit norepinephrine release in the synaptic gap (10).

The B-AR are classically divided into 3 subtypes (B1, B2, and B3), having a fourth subtype that has not been well characterized. The $B 1-A R$ is the dominant subtype in the non-failing heart, representing $70-80 \%$ of $\beta$ ARs $(11,12)$. $B 1$ and $B 2$ receptors are pharmacologically distinguished by differences in affinities for both receptor agonists and selective antagonists. Although both receptors are stimulated by isoproterenol, a nonselective full agonist, the binding affinity for epinephrine is higher (10- to 30-fold) for the B1-AR subtype (13). Knowledge of B3-AR is poor; it probably acts by regulating metabolic functions and contributing to negative inotropism and myocardial relaxation. It also seems to regulate nitric oxide production (14).

B-AR signaling and differences between B-AR subtypes are also important for the understanding of adrenergic system function. Both $\beta 1$ and $\beta 2$ subtypes are coupled to $\mathrm{G}_{\mathrm{s}}$ protein, which stimulates adenylyl cyclases, resulting in the conversion of ATP to cAMP, which in turn binds to regulator subunits of protein kinase-A (PKA) and phosphorylation of a number of target intracellular proteins. However, unlike B1-ARs, B2ARs couple to a number of signaling pathways in addition to the $\mathrm{G}_{\mathrm{s}}$-dependent pathway. The $32-A R$ can bind to $G_{i}$, with negative inotropic effects, preferentially doing so when in the phosphorylated form. Furthermore, the B2-AR appears to modulate several types of G-protein-independent signaling, and recently the association of B2-AR with an anti-apoptotic role has been described (see below). These differences in post-receptor coupling have physiological conse- quences in the pathophysiology of heart failure (15).

There are also differences between $B 1$ and 32 -ARs regarding their ability to promote apoptosis, a process implicated in myocardial remodeling and HF. While activation of $ß 1$-ARs results in an increased rate of cardiomyocyte apoptosis, B2-AR coupling to $\mathrm{G}_{\mathrm{i}}$ seems to be cardioprotective. This antiapoptotic effect is probably linked to coupling to the phosphatidylinositol 3 kinase pathway $(16,17)$.

\section{The adrenergic system in the failing heart}

Conditions involving contractile cardiac dysfunction result in hemodynamic overload, which activates several adaptive mechanisms. Thus, in HF in the presence of systolic dysfunction, adrenergic activation is an important response to support cardiac work at minimal effective levels. Levels of circulating norepinephrine are increased in patients with HF, reflecting adrenergic system activation. This results from increased release, as well as reduced uptake of norepinephrine. Nevertheless, in chronic situations, an initially adaptive response of the adrenergic system becomes inadequate or even harmful. In fact, increased plasma norepinephrine levels are associated with severity and a worse prognosis in HF (18-20). To avoid perpetuation of this situation, regulatory mechanisms have been developed aiming to attenuate adrenergic responses.

$\mathrm{AR}$ are the key for adrenergic system regulation and in pathologic situations their function and distribution are dramatically altered $(7,9,21)$. Desensitization and downregulation of AR are the principal mechanisms observed in HF.

Desensitization is the mechanism by which cells decrease effector responses, despite the presence of ligands, usually a defect in G-protein coupling. Multiple regulatory adjustments produce desensitization of 
downstream effector responses in the failing heart, resulting in a marked attenuation of the response to catecholamines. In heart failure, both B1- and B2-ARs are significantly desensitized due to uncoupling of the receptor from its respective signaling pathways $(6,22)$. Two molecular processes are involved: increased B-AR phosphorylation and up-regulation of the $\mathrm{G}_{\mathrm{i}}$ protein. Phosphorylation is primarily mediated by increased abundance and activity of G-protein-coupled receptor kinases, and is directly dependent on agonist occupancy. Thus, phosphorylation is stimulated by sympathetic overactivity as seen in HF. These desensitization processes lead to reduction in the amount of cAMP being generated for a given adrenergic stimulation (23). Thus, cardiomyocytes suffer the consequences of functioning at higher levels of adrenergic activation to maintain the cardiac work. Potentially damaging cAMP-independent pathways may become more activated and other cAMPdependent pathways can be activated besides that responsible for controlling cardiac contractility, which may make adrenergic activation even more myopathic.

Down-regulation is the reduction in activated receptor expression on the cell membrane. Receptors are continuously translocating from the membrane into endosomes at a slow rate but this rate is dramatically increased in the presence of an agonist. From the endosomes, receptors can be either recycled back to the plasma membrane or routed to lysosomes for degradation $(22,24)$. In HF patients, selective B1-AR down-regulation occurs as the proportion of $\beta 1: 32-A R s$ approximates 50:50, shifting from the physiologic ratio of 76:24 (12). This decrease in receptor numbers is in part a product of elevated lysosomal degradation of preexisting receptors as well as decreased mRNA and protein synthesis $(22,25)$. Also, overstimulation leads to PKA- and PKC-mediated phosphorylation of B-receptors, which in turn will transform the receptors into bet- ter targets for internalization. In addition, phosphorylation by B-AR kinase also mediates receptor down-regulation as phosphorylated $B$-receptors bind to $B$-arrestin, which interferes with receptor coupling with $G_{s}$ proteins and enhances internalization and degradation of the receptors (22). It has been suggested that the selective B1-AR downregulation in $\mathrm{HF}$ is related in part to a reduction in B1-AR synthesis, as indicated by its reduced mRNA levels, which are more evident for B1-AR, as well as increased lysosomal degradation due to differential internalization pathways $(6,22,26)$. However, the reason for $\mathrm{B} 2-\mathrm{AR}$ refractoriness to downregulation in HF is not entirely clear since in a number of experimental model systems the B2-AR is actually more profoundly downregulated $(6,22,27)$.

In summary, chronic HF generates persistent adrenergic activation, which becomes indispensable to maintain minimal myocardial work necessary to supply organism requirements. However, the more the adrenergic system is activated the higher is its toxicity; as a protective mechanism, desensitization occurs, by changes in the number and the function of AR. This adaptive pathway thus stimulates more activation and again myocardial damage, in a vicious and progressive cycle. This milieu seems to represent an important factor for the progressive status of myocardial dysfunction and remodeling in HF.

\section{Adrenergic receptor polymorphisms and heart failure}

A polymorphism is a genetic variant that occurs in at least $1 \%$ of the population, similarly to the human $\mathrm{ABO}$ blood groups. By setting the cutoff at $1 \%$, it excludes spontaneous mutations that may have occurred in - and spread through the descendants of - a single family. Since proteins are gene products, polymorphic versions are simply reflections of allelic differences in the gene, i.e., allelic dif- 
ferences in DNA (28). Recently, several polymorphic variants of proteins that constitute AR have been identified and their role in HF is being actively investigated.

Since several receptors and regulatory pathways work simultaneously, the final consequence of a single mutation is difficult to predict. Genetic studies in animal models of $\mathrm{HF}$ and in $\mathrm{HF}$ patients have explored the consequences of specific AR polymorphisms $(29,30)$. These studies have shown that polymorphisms can alter receptor efficiency by regulating G-protein binding, as well as its sensitivity to down-regulatory stimuli. Clinical studies have explored the role of these polymorphisms in HF risk, progression and even response to therapy. We will discuss the main AR polymorphisms identified and their influence on HF (Table 1).

\section{ß1-Adrenergic receptor polymorphisms}

Two main polymorphisms were identified for the B1-AR, at codons 49 and 389. The B1Ser49Gly is an adenine to guanine substitution at nucleic acid 145, which results in a serine to glycine substitution in the position of amino acid 49 , located in the extracellular region of the $\beta 1-A R(31,32)$. The functional properties of this polymorphism were investigated in vitro. B1-49Gly receptors showed higher activity in addition to a greater response to inhi- bition by metoprolol, as well as greater desensitization and down-regulation when chronically stimulated (31). It has been speculated that a higher regulating capacity of the adrenergic system could be beneficial and protective for patients with HF. In experimental models, despite a similar affinity for agonists and antagonists of B1-49Ser and B1-49Gly variants, the down-regulation promoted by prolonged stimulation was greater for B149Gly, reinforcing the idea that this can be a protective mechanism for patients with HF (32).

In order to evaluate the influence of this polymorphism on HF risk and prognosis, its prevalence was determined in 184 patients with idiopathic HF and 77 control subjects. Although the prevalence of the polymorphism was similar for patients and controls, the long-term prognosis was better for patients with the 81-49Gly allele (a 5-year survival of 62 vs $39 \%$ for patients with B149Ser, $\mathrm{P}=0.005$ ) (33). This study agrees with speculations of experimental studies, in which the altered function of the receptor with the 81-49Gly allele can result in a myocardial protective effect in HF. Moreover, Podlowski and co-workers (34) observed that the presence of the B1-49Gly allele is more prevalent in patients with idiopathic cardiomyopathy. In fact, the role of B1Ser49Gly and other AR polymorphisms in

Table 1. Adrenergic receptor polymorphisms and heart failure.

\begin{tabular}{|c|c|c|}
\hline Polymorphism & In vitro effects & Possible clinical consequences \\
\hline B1-Ser49Gly & $\begin{array}{l}\text { Uncertain } \\
\text { Exaggerated down-regulation? }\end{array}$ & $\begin{array}{l}\text { Greater regulating capacity of the adrenergic system }(31,32) \\
\text { Better prognosis }(33)\end{array}$ \\
\hline B1-Arg389Gly & $\begin{array}{l}\text { Increased function (acutely) } \\
\text { Increased down-regulation }\end{array}$ & $\begin{array}{l}\text { Increased response at the cardiomyocytes (35-37) } \\
\text { Poor exercise capacity (40) } \\
\text { Increased risk of ventricular arrhythmias (41) } \\
\text { Increased response to B-blockade (37) }\end{array}$ \\
\hline B2-Thr164lle & Decreased affinity for G-protein coupling & $\begin{array}{l}\text { Worse contractile myocardial function (29) } \\
\text { Worse prognosis (42) }\end{array}$ \\
\hline 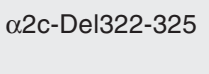 & Decreased function & $\begin{array}{l}\text { Increased norepinephrine release at the synapse level (44) } \\
\text { Increased risk of heart failure (38) }\end{array}$ \\
\hline
\end{tabular}

References are given in parentheses. 
progression and prognosis of HF represents a rapidly evolving field which needs further investigation for a more comprehensive understanding.

Another $B 1-A R$ polymorphism is $B 1$ Arg389Gly, which results from the replacement of arginine with glycine at a critical point for G-protein coupling, with less coupling affinity for the B1-389Gly allele (35). The allelic prevalence is approximately $70 \%$ for B1-389Arg and 30\% for B1-389Gly $(35,36)$. In transgenic mice, young Arg389 mice had enhanced receptor function and contractility compared to Gly389 mice. However, older Arg389 mice presented a phenotypic switch, showing decreased $\beta$-agonist signaling and cardiac contractility (37). In fact, the B1-389Arg allele seems to be associated with an increased and hyperactive signaling in initial stages, but it reduces signaling in later stages, with less receptor binding and ventricular contraction. In addition, Arg389 mice had a better hemodynamic response and ventricular function improvement with $\beta$-blockade, suggesting that this polymorphism can influence the therapeutic response to B-blockers (37). A retrospective analysis of the MERIT study evaluated the influence of the B1-389Arg allele on the therapeutic response to $\beta$-blockers in patients with symptomatic HF. However, there was no association of the B1-Arg389Gly polymorphism with survival or with response to B-blocker therapy in this analysis (36).

To investigate whether this polymorphism represents a risk for the development of HF, Small et al. (38) studied 159 patients with HF (ischemic and idiopathic) and 189 controls. There was no increase in risk with B1-389Arg alone. However, there was a marked increase in risk for HF among blacks who concomitantly had the B1-389Arg allele and another polymorphism related to $\alpha$ $\mathrm{AR}(\mathrm{OR}=10.11,95 \% \mathrm{CI}=2.11$ to 48.53$)$. Among white subjects, allele frequencies were too low to permit an adequate assessment of risk. In another study, the frequency of ß1-Arg389Gly polymorphism was evaluated in 426 patients with idiopathic dilated cardiomyopathy (39). Although no association was found with risk or severity of HF, the authors speculated that this polymorphism may relate to response to ß-blockade. Further studies are needed to clarify this hypothesis.

The association of B1-Arg389Gly polymorphism with clinical characteristics of HF was also studied. In one study, this polymorphism was a significant determinant of exercise capacity (40). Patients with the $B 1$ 389Gly allele had significantly lower peak oxygen consumption than those with $B 1$ 389Arg, suggesting that early detection of this polymorphism might be useful to identify patients at risk for depressed exercise capacity and therefore candidates for specific tailored therapy.

Since B1-AR appears to be important in the induction of ventricular arrhythmia, the association between the 31 -Arg389Gly polymorphism and the occurrence of ventricular tachycardia was assessed in Japanese patients with idiopathic dilated cardiomyopathy. The B1-389Gly allele suppressed the occurrence of this arrhythmia, suggesting a possible decreased sudden death risk associated with this allele (41). Thus, this polymorphism may represent a tool for the assessment of risk and for planning specific therapies for HF patients.

\section{ß2-adrenergic receptor polymorphisms}

Several polymorphisms of $\beta 2$-AR have been described, but the polymorphic variant in amino acid 164 (B2-Thr164Ile) is the best studied. Most individuals are homozygous for B2-164Thr (95\%), which more strongly activates the receptor than the $32-164$ Ile variant. In transgenic mice, the presence of the B2-164Ile allele resulted in depressed myocardial contractile function (29). Liggett et al. (42) studied the influence of this polymorphism in 259 patients with idiopathic or 
ischemic HF in relation to risk of death or cardiac transplantation. The 1-year survival of patients with the B2-164Ile allele was $42 \%$ compared with $76 \%$ for patients harboring the wild-type 32 -AR (Figure 2). These investigators concluded that patients with the B2-164Ile allele and HF might be candidates for earlier aggressive intervention or cardiac transplantation. Other polymorphisms of the B2-AR in this same study (B2Arg16Gly and B2-Gln27Glu) were not associated with HF risk or prognosis.

\section{$\alpha$-adrenergic receptor polymorphisms}

$\alpha$-ARs are important receptors which regulate norepinephrine release into the synaptic gap, and variations in their function may lead to higher susceptibility to HF (43). One polymorphism of $\alpha 2 \mathrm{c}-\mathrm{AR}$, a deletion of 4 amino acids ( $\alpha 2 c-D e l 322-325)$, results in a decreased function of this receptor, with lower auto-inhibitory activity and higher norepinephrine levels (44). This deletion was studied in 159 patients with idiopathic or ischemic HF, and was associated with a higher risk of HF in black patients (38). This study demonstrated that polymorphisms of different receptors probably act in a synergistic way to influence predisposition to HF. When both the $\alpha 2 \mathrm{c}$-Del322-325 polymorphism and the B1-Arg389 allele were present in black patients, the risk was increased by approximately 10 -fold. Characterization of these genotypes may be useful to identify individuals at higher risk for HF and, therefore, candidates for early preventive strategies. Racial differences in allele frequencies remain to be better clarified (38).

\section{Adrenergic receptor polymorphisms and heart failure treatment}

A better understanding of the physiopathological process involved in HF development and progression has brought dramatic changes in its treatment over the last few years. The elucidation of the role of the adrenergic system was one of the most important advances in this regard. Initially seen as a vital compensatory mechanism, the incessant activation of the adrenergic system turned out to be viewed as one of the greatest villains in HF progression. With this new paradigm, adrenergic system blockade became a crucial part of HF treatment. In fact the use of ß-blockers is associated with better outcomes in several HF clinical trials. This beneficial effect is thought to be due to multiple mechanisms which include improved calcium handling by the sarcoplasmatic reticulum, increased gene expression of $\alpha$-myosin heavy chain, and more specifically re-expression and re-coupling of $B 1$ and $\beta 2$ receptors by myocytes allowing the return of a more physiological response to the adrenergic drive (45).

However, the results of some clinical trials have raised questions related to this concept. While the benefit of $\beta$-blockers is well established, primarily sympatholytic agents seem to have deleterious effects on patients with HF (46). One example is moxonidine, which increased mortality in patients with $\mathrm{HF}$ in the MOXCON study, an effect primarily attributed to its strong sympatho-

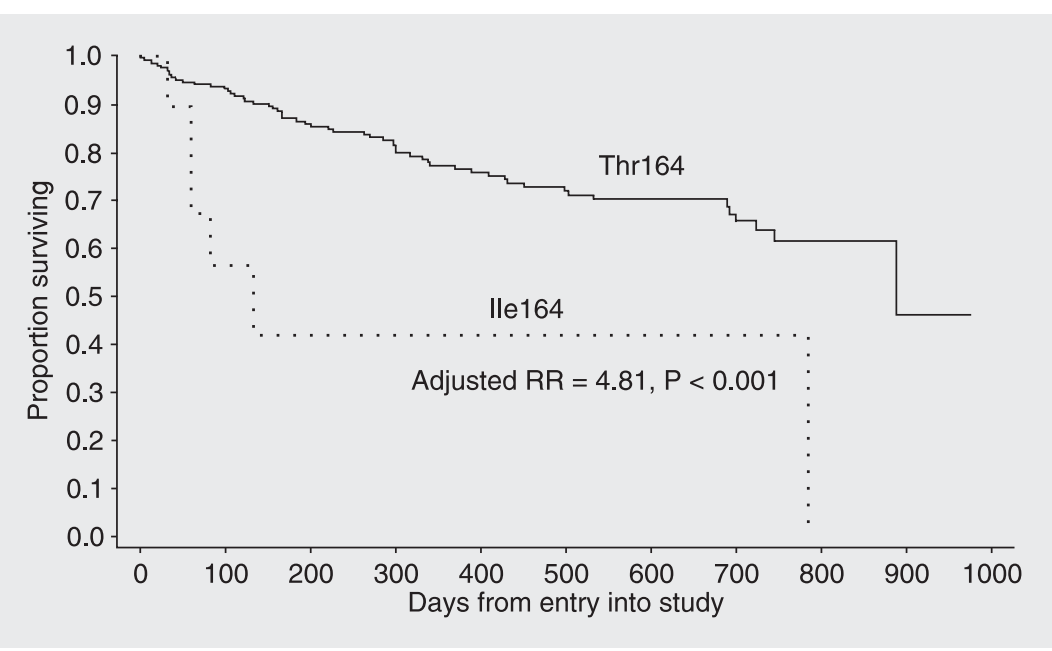

Figure 2. Survival of patients with heart failure with the wild-type B2-adrenergic receptor (continuous line) or the B2-164lle allele (dotted line). Reproduced from Liggett et al. (Ref. 42), with permission from the Journal of Clinical Investigation. 
lytic action (47). Another agent, bucindolol (a B-blocker and a sympatholytic agent), showed no benefit in black patients and in those in functional class IV, suggesting that certain subpopulations may be more susceptible to the deleterious effects of adrenergic suppression (48). One hypothesis for these findings is that sympatholytic agents promote removal of adrenergic support, making unfeasible the adrenergic recruitment when necessary to keep cardiac function. With the use of B-blockers, on the other hand, inhibition can be easily reversed whenever necessary through norepinephrine recruitment.

The altered function of AR and its influence on the risk and therapeutic response of HF patients may represent the link between AR polymorphisms and certain characteristics in specific populations. An example is the already mentioned study of Small et al. (38) in which the presence of the B1-Arg389 allele and $\alpha 2 c-D e l 322-325$ polymorphism had synergistic effects increasing HF risk in black patients. Through the understanding of the genetics of the adrenergic system it may be possible to tailor therapy to patients more inclined to respond to specific interventions, rather than the current situation (economically unfeasible) of treating a large number of patients to effectively benefit a minority. It is possible to speculate, for instance, that the black patients who had higher mortality with bucindolol were those with $\alpha 2 \mathrm{c}-\mathrm{AR}$ polymorphism exposed to much higher levels of norepinephrine, and who lost the adjusting capacity due to its abrupt interruption (46). Similarly, the association of some polymorphisms with the risk of ventricular tachycardia and survival may help to select patients for high-cost interventions, such as defibrillator implantation.

The fact that in a MERIT sub-study no difference related to B1-Arg398Gly was found in response to $\beta$-blockers, and the synergistic action between polymorphisms of different AR on HF risk, raises the possibility that phenotype determination is more likely a result of the interaction between multiple polymorphisms than the influence of an individual polymorphism $(36,38)$. Thus, the complex influence of the adrenergic system on HF must be considered and understood so that we can advance in the therapeutic approach to this syndrome.

\section{Conclusions}

The role of the adrenergic system (and specifically of AR) in the development and progression of HF has been intensively studied. Genetic studies have provided information regarding receptor functions and its polymorphisms in the complex balance of this system.

The combination of experimental data and, recently, studies on HF patients has provided information and has raised questions that may help to improve the therapeutic approaches for HF. In addition, new information regarding the effects of AR polymorphisms may be the basis for pharmacogenetics, which takes into account genetically mediated variability in HF presentation and response to specific medications to define better individualized approach to $\mathrm{HF}$ patients.

\section{References}

1. Levy D, Kenchaiah S, Larson MG, Benjamin EJ, Kupka MJ, Ho KK, et al. Long-term trends in the incidence of and survival with heart failure. N Engl J Med 2002; 347: 1397-1402.

2. Esler M, Kaye D, Lambert G, Esler D, Jennings G. Adrenergic nervous system in heart failure. Am J Cardiol 1997; 80: 7L-14L.

3. CIBIS-II Investigators and Committees. The Cardiac Insufficiency
Bisoprolol Study II (CIBIS-II): A randomized trial. Lancet 1999; 353: 9-13.

4. MERIT-HF Study Group. Effect of metoprolol $C R / X L$ in chronic heart failure: Metoprolol $\mathrm{CR} / \mathrm{XL}$ randomized intervention trial in congestive heart failure (MERIT-HF). Lancet 1999; 353: 2001-2007.

5. Krum H, Roecker EB, Mohacsi P, Rouleau JL, Tendera M, Coats AJ, 
et al. Effects of initiating carvedilol in patients with severe chronic heart failure: results from the COPERNICUS Study. JAMA 2003; 289: 712-718.

6. Port JD, Bristow MR. Altered beta-adrenergic receptor gene regulation and signaling in chronic heart failure. J Mol Cell Cardiol 2001; 33: 887-905.

7. Bristow MR, Hershberger RE, Port JD, Gilbert EM, Sandoval A Rasmussen $\mathrm{R}$, et al. Beta-adrenergic pathways in nonfailing and failing human ventricular myocardium. Circulation 1990; 82: I-12-I-25.

8. Hajjar RJ, MacRae CA. Adrenergic receptor polymorphisms and heart failure. N Engl J Med 2002; 347: 1196-1199.

9. Brodde OE, Bruck H, Leineweber K, Seyfarth T. Presence, distribution and physiological function of adrenergic and muscarinic receptor subtypes in the human heart. Basic Res Cardiol 2001; 96: 528538.

10. Hein L, Altman JD, Kobilka BK. Two functionally distinct alpha2adrenergic receptors regulate sympathetic neurotransmission. $\mathrm{Na}$ ture 1999; 402: 181-184.

11. Brodde OE. The functional importance of beta 1 and beta 2 adrenoceptors in the human heart. Am J Cardiol 1988; 62: 24C-29C.

12. Bristow MR, Ginsburg R, Umans V, Fowler M, Minobe W, Rasmussen $\mathrm{R}$, et al. Beta 1- and beta 2-adrenergic-receptor subpopulations in nonfailing and failing human ventricular myocardium: coupling of both receptor subtypes to muscle contraction and selective beta 1receptor down-regulation in heart failure. Circ Res 1986; 59: $297-$ 309.

13. Bristow MR, Port JD, Kelly RA. Treatment of heat failure: pharmacological methods. In: Braunwald E, Zipes DP, Libby P (Editors), Heart disease: a textbook of cardiovascular medicine. 6th edn. Orlando: W.B. Saunders; 2001. p 562-599.

14. Gauthier C, Leblais V, Kobzik L, Trochu JN, Khandoudi N, Bril A, et al. The negative inotropic effect of beta3-adrenoceptor stimulation is mediated by activation of a nitric oxide synthase pathway in human ventricle. J Clin Invest 1998; 102: 1377-1384.

15. Chakraborti S, Chakraborti T, Shaw G. Beta-adrenergic mechanisms in cardiac diseases: a perspective. Cell Signal 2000; 12: 499513.

16. Communal C, Singh K, Sawyer DB, Colucci WS. Opposing effects of beta(1)- and beta(2)-adrenergic receptors on cardiac myocyte apoptosis: role of a pertussis toxin-sensitive $\mathrm{G}$ protein. Circulation 1999; 100: 2210-2212.

17. Communal C, Singh K, Pimentel DR, Colucci WS. Norepinephrine stimulates apoptosis in adult rat ventricular myocytes by activation of the beta-adrenergic pathway. Circulation 1998; 98: 1329-1334.

18. Floras JS. Sympathetic activation in human heart failure: diverse mechanisms, therapeutic opportunities. Acta Physiol Scand 2003; 177: 391-398.

19. Francis GS, Benedict C, Johnstone DE, Kirlin PC, Nicklas J, Liang $\mathrm{CS}$, et al. Comparison of neuroendocrine activation in patients with left ventricular dysfunction with and without congestive heart failure. A substudy of the Studies of Left Ventricular Dysfunction (SOLVD). Circulation 1990; 82: 1724-1729.

20. Cohn JN, Levine TB, Olivari MT, Garberg V, Lura D, Francis GS, et al. Plasma norepinephrine as a guide to prognosis in patients with chronic congestive heart failure. N Engl J Med 1984; 311: 819-823.

21. Rodefeld MD, Beau SL, Schuessler RB, Boineau JP, Saffitz JE. Beta-adrenergic and muscarinic cholinergic receptor densities in the human sinoatrial node: identification of a high beta 2-adrenergic receptor density. J Cardiovasc Electrophysiol 1996; 7: 1039-1049.

22. Dzimiri N. Regulation of beta-adrenoceptor signaling in cardiac function and disease. Pharmacol Rev 1999; 51: 465-501.
23. Bristow MR. Changes in myocardial and vascular receptors in heart failure. J Am Coll Cardiol 1993; 22: 61A-71A.

24. Ahmed A. Myocardial beta-1 adrenoceptor down-regulation in aging and heart failure: implications for beta-blocker use in older adults with heart failure. Eur J Heart Fail 2003; 5: 709-715.

25. Hadcock JR, Malbon CC. Down-regulation of beta-adrenergic receptors: agonist-induced reduction in receptor mRNA levels. Proc Natl Acad Sci USA 1988; 85: 5021-5025.

26. Bristow MR, Minobe WA, Raynolds MV, Port JD, Rasmussen R, Ray PE, et al. Reduced beta 1 receptor messenger RNA abundance in the failing human heart. J Clin Invest 1993; 92: 2737-2745.

27. Liang W, Austin S, Hoang Q, Fishman PH. Resistance of the human beta 1-adrenergic receptor to agonist-mediated down-regulation. Role of the $\mathrm{C}$ terminus in determining beta-subtype degradation. $J$ Biol Chem 2003; 278: 39773-39781.

28. Kimball JW. Kimball's Biology Pages. http://home.comcast.net/ john.kimball1/BiologyPages/. Accessed December 12, 2004.

29. Turki J, Lorenz JN, Green SA, Donnelly ET, Jacinto M, Liggett SB. Myocardial signaling defects and impaired cardiac function of a human beta 2-adrenergic receptor polymorphism expressed in transgenic mice. Proc Natl Acad Sci USA 1996; 93: 10483-10488.

30. McGraw DW, Forbes SL, Kramer LA, Liggett SB. Polymorphisms of the 5' leader cistron of the human beta2-adrenergic receptor regulate receptor expression. J Clin Invest 1998; 102: 1927-1932.

31. Levin MC, Marullo S, Muntaner O, Andersson B, Magnusson Y. The myocardium-protective Gly-49 variant of the beta 1-adrenergic receptor exhibits constitutive activity and increased desensitization and down-regulation. J Biol Chem 2002; 277: 30429-30435.

32. Rathz DA, Brown KM, Kramer LA, Liggett SB. Amino acid 49 polymorphisms of the human beta1-adrenergic receptor affect agonistpromoted trafficking. J Cardiovasc Pharmacol 2002; 39: 155-160.

33. Borjesson M, Magnusson Y, Hjalmarson A, Andersson B. A novel polymorphism in the gene coding for the beta(1)-adrenergic receptor associated with survival in patients with heart failure. Eur Heart $J$ 2000; 21: 1853-1858.

34. Podlowski S, Wenzel K, Luther HP, Muller J, Bramlage P, Baumann $\mathrm{G}$, et al. Beta1-adrenoceptor gene variations: a role in idiopathic dilated cardiomyopathy? J Mol Med 2000; 78: 87-93.

35. Mason DA, Moore JD, Green SA, Liggett SB. A gain-of-function polymorphism in a G-protein coupling domain of the human beta1adrenergic receptor. J Biol Chem 1999; 274: 12670-12674.

36. White HL, De Boer RA, Maqbool A, Greenwood D, van Veldhuisen DJ, Cuthbert R, et al. An evaluation of the beta-1 adrenergic receptor Arg389Gly polymorphism in individuals with heart failure: a MERIT-HF sub-study. Eur J Heart Fail 2003; 5: 463-468.

37. Mialet PJ, Rathz DA, Petrashevskaya NN, Hahn HS, Wagoner LE, Schwartz A, et al. Beta 1-adrenergic receptor polymorphisms confer differential function and predisposition to heart failure. Nat Med 2003; 9: 1300-1305.

38. Small KM, Wagoner LE, Levin AM, Kardia SL, Liggett SB. Synergistic polymorphisms of beta1- and alpha2C-adrenergic receptors and the risk of congestive heart failure. N Engl J Med 2002; 347: 11351142.

39. Tesson F, Charron P, Peuchmaurd M, Nicaud V, Cambien F, Tiret L, et al. Characterization of a unique genetic variant in the beta1adrenoceptor gene and evaluation of its role in idiopathic dilated cardiomyopathy. CARDIGENE Group. J Mol Cell Cardiol 1999; 31: 1025-1032.

40. Wagoner LE, Craft LL, Zengel P, McGuire N, Rathz DA, Dorn GW, et al. Polymorphisms of the beta1-adrenergic receptor predict exercise capacity in heart failure. Am Heart J 2002; 144: 840-846. 
41. Iwai C, Akita H, Shiga N, Takai E, Miyamoto $Y$, Shimizu M, et al. Suppressive effect of the Gly389 allele of the beta1-adrenergic receptor gene on the occurrence of ventricular tachycardia in dilated cardiomyopathy. Circ J 2002; 66: 723-728.

42. Liggett SB, Wagoner LE, Craft LL, Hornung RW, Hoit BD, McIntosh $\mathrm{TC}$, et al. The lle164 beta2-adrenergic receptor polymorphism adversely affects the outcome of congestive heart failure. J Clin Invest 1998; 102: 1534-1539.

43. Parker JD, Newton GE, Landzberg JS, Floras JS, Colucci WS. Functional significance of presynaptic alpha-adrenergic receptors in failing and nonfailing human left ventricle. Circulation 1995; 92: 1793-1800.

44. Small KM, Forbes SL, Rahman FF, Bridges KM, Liggett SB. A four amino acid deletion polymorphism in the third intracellular loop of the human alpha 2C-adrenergic receptor confers impaired coupling to multiple effectors. J Biol Chem 2000; 275: 23059-23064.

45. Sabbah HN. Biologic rationale for the use of beta-blockers in the treatment of heart failure. Heart Fail Rev 2004; 9: 91-97.

46. Bristow M. Antiadrenergic therapy of chronic heart failure: surprises and new opportunities. Circulation 2003; 107: 1100-1102.

47. Coats AJ. Heart Failure 99 - the MOXCON story. Int J Cardiol 1999; 71: 109-111.

48. Beta-blocker Evaluation of Survival Trial Investigators. A trial of the beta-blocker bucindolol in advanced chronic heart failure. $N$ Engl J Med 2001; 344: 1659-1667. 